\title{
A GOVERNANÇA EM SUAS \\ MÚlTIPLAS FORMAS DE EXPRESSÃO: \\ O DELINEAMENTO CONCEITUAL \\ DE UM FENÔMENO COMPLEXO
}

ORLANDO VILLAS BÔAS FILHO ${ }^{\dagger}$

RESUMO: Este artigo analisa o fenômeno da governança em suas diversas formas de expressão. Assim, em primeiro lugar, com o intuito de sublinhar a importância do referido fenômeno, procura situá-lo, em termos introdutórios, no contexto contemporâneo. Feita essa introdução, é realizado um breve contraste entre os conceitos de governança e de governo. Em seguida, para explicitar a complexidade do fenômeno da governança, é empreendia uma análise de suas diversas formas de expressão. Para tanto, pelo ângulo da sociologia jurídica, são analisadas, sucessivamente, a "governança corporativa", a "governança global", a "governança dos blocos regionais", a "governança nacional" e, finalmente, a "governança local". Após essa análise, a governança é abordada como instrumento de participação para a tomada de decisões a partir de uma sistemática oposta ao modelo top down. Por fim, em termos conclusivos, é feito um exame da progressiva centralidade assumida pelo conceito no debate contemporâneo e da polissemia que o caracteriza.

Palavras-Chave: Governança; Governo; Regulação Jurídica; Sociologia Jurídica; Tomada de Decisão.

\footnotetext{
† Professor da Faculdade de Direito da Universidade de São Paulo e Professor Associado da Faculdade de Direito da Universidade Presbiteriana Mackenzie. Graduação e Licenciatura Plena em História pela Universidade de São Paulo. Graduação em Direito pela Pontifícia Universidade Católica de São Paulo. Graduação em Filosofia pela Universidade de São Paulo. Mestrado em Direito e Doutorado em Direito, na área de concentração Filosofia e Teoria Geral do Direito, pela Universidade de São Paulo. Pós-Doutorado na Université de Paris X - Nanterre, França. PósDoutorado na École Normale Supérieure de Paris, França.
} 
ABSTRACT: This article analyzes the phenomenon of governance in its various forms of expression. Thus, in the first place, in order to underline the importance of this phenomenon, it seeks to situate it, in introductory terms, in the contemporary context. After this introduction, a brief contrast is made between the concepts of governance and government. Then, to explain the complexity of the governance phenomenon, an analysis of its various forms of expression is undertaken. In order to do so, "corporate governance", "global governance", "governance of the regional blocs", "national governance" and, finally, "local governance" are analyzed successively. After this analysis, governance is approached as an instrument of participation to make decisions based on a system opposed to the top down model. Finally, in conclusive terms, an examination is made of the progressive centrality assumed by the concept in contemporary debate and the polysemy that characterizes it.

KEYWORDS: Governance; Government; Legal Regulation; Legal Sociology; Decision Making. 


\section{SUMÁRIO:}

I. INTRODUÇÃO ........................................................................................673

II. Do GOVERNO À GOVERNANÇA ...........................................................676

III. O FENÔMENO da GOVERNANÇA ENFOCADO EM SUAS MÚLTIPLAS FORMAS DE EXPRESSÃO ….............................681

1. A Governança Empresarial/Corporativa .............................683

2. A Governança Global ...............................................................684

3. A Governança dos Blocos Regionais ......................................688

4. A Governança Nacional............................................................690

5. A Governança Territorial/Local............................................692

IV. GovERNANÇA E TOMADA DE DECISÃo ............................................693

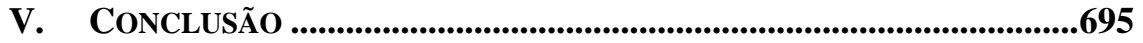

VI. REFERÊNCIAS......................................................................................698

\section{TABLE OF CONTENTS:}

I. INTRODUCTION .........................................................................673

II. FROM GOVERNMENT TO GOVERNANCE...........................................676

III. The Governance Phenomenon FOCUSED IN ITS MULTIPLE WAYS OF EXPRESSION...........................681

1. The Enterprise / Corporate Governance ..............................683

2. The Global Governance.............................................................684

3. The Governance in Regional Blocks......................................688

4. The National Governance........................................................690

5. The Territorial / Local Governance .......................................692

IV. GoVERNANCE AND DECISION MAKING ..............................................693

V. CONCLUSION ...........................................................................................695

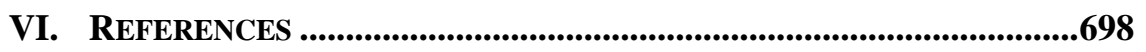




\section{INTRODUÇÃO}

A questão da governança tem suscitado amplo interesse nas análises contemporâneas. Diversos autores, sob as mais variadas perspectivas, enfocam-na procurando, entre outras coisas, delinear seu contorno conceitual, suas distintas formas de manifestação e suas relações com a globalização, com as mutações em curso nas formas de regulação social, com a participação mais ampla na tomada de decisões, com a democracia e com o Estado de Direito. Assim o conceito de governança remete a uma experiência extremamente complexa cujas vias de análise parecem ser, à primeira vista, inesgotáveis. Aliás, nesse particular, vários são os autores que sublinham o caráter paradigmático desse conceito para a compreensão do que está implicado em um cenário, marcado pela globalização, em que "governar sem governo" parece ser uma realidade cada vez mais efetiva. ${ }^{1}$

Desse modo, a primeira providência importante no tratamento da questão consiste em definir, ainda que em termos provisórios, o que se está entendendo por governança. A respeito, procurando analisar, historicamente, a origem do termo, Philippe Moreau Defarges, enfatiza que ele teria surgido na França, no século XII, consignando um sentido técnico de direção dos "bailiados" (bailliages). ${ }^{2}$ Em seguida, os historiadores ingleses da Idade Média o teriam utilizado para caracterizar o modo de organização do poder feudal. ${ }^{3}$ Por fim, o termo teria ressurgido no último quarto do século $X X$, na tradição anglófona, como uma das noções fundamentais no âmbito das empresas e das organizações. ${ }^{4} \mathrm{O}$ autor sublinha, ainda, que a governança, inscrevendo-

\footnotetext{
${ }_{1}^{1}$ Acerca do caráter paradigmático do conceito de governança, ver, por exemplo: ARNAUD, André-Jean. La gouvernance. Un outil de participation. Paris: Librairie Générale de Droit et de Jurisprudence-Lextenso, 2014, p. 293 e ss.; CAPELLER, Wanda; SIMOULIN, Vincent. La gouvernance: du programme de recherche à la transdisciplinarité (Présentation). Droit et Société, v. 54, 2, 2003, p. 301-305; MOREAU DEFARGES, Philippe. La gouvernance. $5^{e}$ éd. Paris: Presses Universitaires de France, 2015, p. 7.

${ }^{2}$ De acordo com o dicionário Petit Robert, Bailiado (Bailliage) refere-se a circunscrições administrativas e judiciárias da França medieval colocadas sob a autoridade de um Bailli (termo do francês antigo que, derivado do latim bajulus, servia para designar uma espécie de governador) que as administrava em nome do rei ou de um senhor. ${ }^{3}$ Cf. MOREAU DEFARGES, Philippe. La gouvernance. $5^{e}$ éd. Paris: Presses Universitaires de France, 2015, p. 3.

${ }^{4}$ Em sentido semelhante, Étienne Le Roy observa que "la notion de gouvernance, d'origine française et anglo-normande, introduite dans le common law, transposée dans
} 
se em uma constelação de ideias produzidas no âmbito da sociedade contemporânea, exprimiria os novos modos de gestão social produzidos pelas revoluções da informação. ${ }^{5}$

Procurando fixar o sentido do termo governança no horizonte da sociedade globalizada, André-Jean Arnaud enfatiza a importância de distingui-lo, conceitualmente, dos termos "governo", "governabilidade" e "governamentalidade". ${ }^{6}$ Nesse sentido, após aludir especialmente às

le droit américain puis redécouverte par les experts de la Banque mondiale peut apparaître comme un des nouveaux gadgets de la coopération internationale." LE ROY, Étienne. Le jeu des lois: une anthropologie "dynamique" du Droit: avec des consignes et des conseils au "jeune joueur juriste". Paris: Librairie Générale de Droit et de Jurisprudence, 1999, p. 294. Referindo-se à governança, André-Jean Arnaud observa que "Dès le 13e siècle, sinon au 15e, l'usage en est attesté en français au sens de gouvernement, puis de juridiction. Dans le langage commun, c'est à la conduite personnelle que le mot se réfère, avant de désigner, sous la plume de Mme de Sévigné, la charge de gouvernante." ARNAUD, André-Jean. Critique de la raison juridique 2.

Gouvernants sans frontières entre mondialisation et post-mondialisation. Paris: Librairie Générale de Droit et de Jurisprudence, 2003, p. 330-331. A respeito, ver também: DELMAS-MARTY, Mireille. Les forces imaginantes du droit. 1, le relatif et l'universel. Paris: Seuil, 2004, p. 37-38.

${ }^{5}$ MOREAU DEFARGES, Philippe. La gouvernance. 5e éd. Paris: Presses Universitaires de France, 2015, p. 3. A respeito, ver: DELMAS-MARTY, Mireille. Gouvernance et état de droit. In: Séverine Bellina; Hervé Magro; Violaine de Villemeur (Dirs.). La

Gouvernance Démocratique: un nouveau paradigme pour le développement? Paris: Karthala, 2008, p. 215-217.

' Após aludir à imprecisão da noção de "governamentalidade", especialmente na forma em que foi definida por Michel Foucault, André-Jean Arnaud ressalta que “tandis que 'gouvernement' désignera l'exercice du pouvoir lié à la souveraineté étatique, et 'gouvernabilité', le degré d'effectivité du précédent, 'gouvernance' va, tout en recouvrant des contenus divers, servir à désigner un ensemble de prescriptions en matière de gestion administrative e politique." ARNAUD, André-Jean. La gouvernance. Un outil de participation. Paris: Librairie Générale de Droit et de Jurisprudence-Lextenso, 2014, p. 22. Acerca da noção de "governamentalidade", ver: FOUCAULT, Michel. A governamentalidade. In: Michael Foucault. Microfísica do poder. 11 ${ }^{a}$ ed. Rio de Janeiro, RJ: Graal, 1993, p. 277-293. A respeito, ver, por exemplo: CHEVALLIER, Jacques. L'État post-moderne. $3^{3}$ éd. Paris: Librairie Générale de Droit et de Jurisprudence, 2008, p. 238; ARNAUD, André-Jean. Critique de la raison juridique 2. Gouvernants sans frontières entre mondialisation et postmondialisation. Paris: Librairie Générale de Droit et de Jurisprudence, 2003, p. 331332; FONSECA, Márcio Alves da. Michel Foucault e o Direito. 2ª ed. São Paulo, SP: 
perspectivas de Bob Jessop e Patrick Le Galès, Arnaud afirma que a governança poderia ser compreendida como um estilo de gestão e de administração de questões públicas e privadas não emanado da ordem governamental ou de decisões fundadas em um ente soberano, na medida em que estaria fundado em uma autoridade partilhada. ${ }^{7}$ Em sentido semelhante, Jacques Chevallier, ao enfocar a governança, também alude às questões da "governabilidade" e da "ingovernabilidade". ${ }^{8}$ Contrastando as noções de governo e de governança, Philippe Moreau Defarges sublinha que esta última se caracterizaria por ser um sistema que rejeita toda e qualquer hierarquia e onde nada é fixo e tudo é fluido. ${ }^{9}$

Portanto, pode-se afirmar que é nesse horizonte que se inscreve a questão da governança. Jacques Chevallier, a partir da clássica definição de James Nathan Rosenau, a define como um conjunto de mecanismos complexos de interação que se desenvolvem entre uma multiplicidade de atores, públicos, privados e autônomos, com o intuito de produzir regras elaboradas coletivamente. ${ }^{10}$ A respeito, André-Jean Arnaud sublinha o impacto da governança - entendida como uma dinâmica complexa de

Saraiva, 2012, p. 188 e ss.; FONSECA, Márcio Alves da; GONÇALVES, Guilherme Leite; CANAPARO, Claudio. Governabilité. In: André-Jean Arnaud (Dir.).

Dictionnaire de la Globalisation: Droit, Science Politique, Sciences Sociales. Paris: Librairie Générale de Droit et de Jurisprudence, 2010, p. 263-266; HARDT, Michael; NEGRI, Antonio. Empire. Cambridge, MA: Harvard University Press, 2000, p. 327-328; GROS, Frédéric. Michel Foucault. $4^{\mathrm{a}}$ ed. Paris: Presses Universitaires de France, 2010, p. 83-90.

${ }^{7}$ Cf. ARNAUD, André-Jean. La gouvernance. Un outil de participation. Paris: Librairie Générale de Droit et de Jurisprudence-Lextenso, 2014, p. 25. A respeito, ver: JESSOP, Bob. The regulation approach, governance and post-Fordism: alternative perspectives on economic and political change? Economy and society, Vol. 24, 3, 1995, p. 307-333; LE GALÈS, Patrick. Régulation, gouvernance et territoire. In: Jacques Commaille; Bruno Jobert (Dir.). Les métamorphoses de la régulation politique. Paris: Librairie Générale de Droit et de Jurisprudence, 1998, p. 203-240.

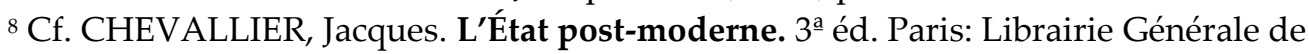
Droit et de Jurisprudence, 2008, p. 237.

${ }^{9}$ MOREAU DEFARGES, Philippe. La gouvernance. $5^{\mathrm{e}}$ éd. Paris: Presses Universitaires de France, 2015, p. 27.

${ }^{10}$ Cf. CHEVALLIER, Jacques. L'État. 2ª ed. Paris: Dalloz, 2011, p. 98. Em sentido semelhante, ver: ARNAUD, André-Jean. La gouvernance. Un outil de participation. Paris: Librairie Générale de Droit et de Jurisprudence-Lextenso, 2014, p. 23-25; e MOREAU DEFARGES, Philippe. La gouvernance. $5^{\mathrm{e}}$ éd. Paris: Presses Universitaires de France, 2015, p. 29. 
relações e inter-relações transformadoras que articulam os mais diversos âmbitos - na erosão do modelo top down de decisão e, especialmente, seu potencial como instrumento de participação no exercício da autoridade política, econômica e/ou administrativa para a gestão dos negócios comuns nos níveis global, regional, nacional, local/territorial e empresarial, abrangendo, ademais, todos os setores (público e privado), sobretudo a sociedade civil. ${ }^{11}$

Diante disso, este artigo pretende examinar a complexidade assumida pela governança no contexto atual. Assim, inicialmente, será realizada uma análise conceitual que contrasta governo e governança. Em seguida, focalizar-se-á o delineamento conceitual dado pela abordagem sociológica ao fenômeno da governança em suas múltiplas formas de expressão. Para tanto, será reconstruída especialmente a análise feita por André-Jean Arnaud acerca dessa questão nos planos empresarial/corporativo, global, regional, nacional e local para, a partir dela, explicitar a complexidade que a caracteriza. Por fim, uma breve conclusão, enfatizará a progressiva centralidade assumida por tal conceito na discussão contemporânea.

\section{Do GOVERno À GOVERNANÇA}

Conforme mencionado, com o intuito de definir o que está implicado no conceito de governança, é preciso delimitá-lo claramente em relação a outros que dele se aproximam, tais como os de "governo", "governabilidade" e "governamentalidade". ${ }^{12}$ Nesse particular, é importante distinguir governo e governança. Em sua clássica análise, James N. Rosenau já enfatizava que, apesar de se referirem a comportamentos visando a um objetivo, a atividades orientadas para metas e a sistemas de ordenação, os conceitos de governança e de governo não poderiam ser confundidos. Segundo o autor, a ideia de governo sugeriria uma autoridade oficial, dotada de poder de polícia que garantiria a implementação das políticas devidamente instituídas, enquanto a de governança diria respeito a atividades apoiadas em objetivos, que podem ou não derivar de responsabilidades legais e formalmente prescritas sem que seja indispensável a intervenção do

${ }^{11}$ Cf. ARNAUD, André-Jean. La gouvernance. Un outil de participation. Paris: Librairie Générale de Droit et de Jurisprudence-Lextenso, 2014, p. 279.

${ }^{12}$ Cf. ARNAUD, André-Jean. La gouvernance. Un outil de participation. Paris: Librairie Générale de Droit et de Jurisprudence-Lextenso, 2014, p. 21-22. 
poder de polícia. Assim, a governança consistiria em um fenômeno mais amplo do que o governo, de modo a abranger não apenas instituições governamentais, mas também mecanismos informais, de caráter não governamental, por meio dos quais indivíduos e organizações, no âmbito de uma determinada área de atuação, perseguiriam seus interesses próprios. Portanto, a governança expressaria um sistema de ordenação fundado tanto em relações interpessoais como em regras e em sanções explícitas, motivo pelo qual, enquanto sistema de ordenação, implicaria a aceitação da maioria (ou pelo menos dos atores mais poderosos) para poder funcionar ao passo que os governos poderiam, em tese, funcionar mesmo diante de uma forte oposição. ${ }^{13}$

A respeito, contrastando governo e governança, Philippe Moreau Defarges sustenta que se trata de conceitos conexos, pois seu domínio seria, em princípio, o mesmo: a organização e a gestão de estruturas coletivas (empresas, Estados, organizações internacionais etc.). Contudo, sublinha que, apesar disso, eles não se confundiriam, pois os universos em que se desenvolvem seriam distintos, uma vez que os problemas fundamentais enfrentados por um governo seriam a escassez e a unidade (ou seja, como distribuir recursos precários e limitados e como manter a coesão diante da tendência de desagregação), enquanto, no caso da governança, a abundância e a unidade são pressupostas. ${ }^{14}$ Assim, com o intuito de explicitar as diferenças entre governo e governança, o autor propõe o seguinte quadro analítico:

${ }^{13}$ Cf. ROSENAU, James. Governança, Ordem e Transformação na Política Mundial. In: James Rosenau; Ernst-Otto Czempiel (Orgs.). Governança sem Governo: ordem e transformação na política mundial. Trad. Sérgio Bath. Brasília, DF: Editora UnB/Imprensa Oficial do Estado, 2000, p. 15-16.

${ }^{14}$ Cf. MOREAU DEFARGES, Philippe. La gouvernance. $5^{e}$ éd. Paris: Presses Universitaires de France, 2015, p. 27.

2 JOURNAL OF INSTITUTIONAL STUDIES 2 (2016) 
Quadro 1

O contraste entre governo e governança ${ }^{15}$

\begin{tabular}{l|l|l}
\hline & Governo & Governança \\
\hline Domínio & Assuntos públicos & Assuntos coletivos \\
\hline Ambiente & Escassez & Abundância \\
\hline Horizonte & Guerra & Paz \\
\hline Espírito & Vertical / Hierárquico & Horizontal / Democrático \\
\hline Modos decisórios & Ordem / Instrução & Negociação / Processos \\
\hline Finalidade & Manutenção / Unidade & Criatividade / Diversidade \\
\hline Controle / Supervisão & Estado & $\begin{array}{l}\text { Autoridades independentes / } \\
\text { Estado, como recurso último }\end{array}$ \\
\hline
\end{tabular}

Apesar de consignar certas imprecisões, tais como associar a gestão democrática apenas à governança, o quadro proposto por Philippe Moreau Defarges veicula, ainda que de maneira esquemática, um contraste ilustrativo dos conceitos de governo e de governança. A partir desse contraste, fica evidente que o conceito de governo remete a uma organização institucional que procede de maneira verticalizada, ou seja, a partir de uma forma de ordenação hierarquizada (top down), enquanto que o de governança reporta-se a um sistema horizontal, não necessariamente atrelado à autoridade estatal, e ordenado a partir de uma lógica distinta (bottom up). ${ }^{16}$ Assim, conforme observa Bob Jessop, seria possível definir o campo geral dos estudos acerca da governança como aquele concernente à resolução de problemas parapolíticos (no sentido de

${ }^{15}$ Cf. MOREAU DEFARGES, Philippe. La gouvernance. 5 e éd. Paris: Presses

Universitaires de France, 2015, p. 27.

${ }^{16}$ Conforme Moreau Defarges, “la gouvernance n'est pas une entité, c'est un système rejetant toute hiérarchie. Rien n'est censé être fixe, tout est en flux. [...] À l'ère de la gouvernance, le politique, vidé de toute finalité, ne sert plus qu'à surveiller que le jeu social ne se déroule pas trop mal." MOREAU DEFARGES, Philippe. La gouvernance. 5e éd. Paris: Presses Universitaires de France, 2015, p. 27. 
realização de fins coletivos) a partir ou por meio de configurações específicas de instituições, organizações e práticas governamentais (hierárquicas) e extragovernamentais (não hierárquicas). ${ }^{17}$

Assim, segundo André-Jean Arnaud, subvertendo a representação clássica de uma gestão governamental que se realizaria de maneira top down a partir da autoridade soberana de um ente estatal, a governança suporia uma autoridade partilhada. ${ }^{18}$ É, aliás, nesse sentido que, conforme bem o nota Mireille Delmas-Marty, a governança, concebida como uma forma de governar sem governo, demandaria a necessidade de coordenação das relações entre os diversos atores estatais e não estatais (econômicos, cívicos, científicos etc.) que participam do exercício do poder. ${ }^{19}$ Essa associação entre governança e coordenação dos atores é recorrente na literatura que discute o tema. Patrick Le Galès, por exemplo, define a governança como um processo complexo de coordenação de atores, grupos sociais e instituições para a consecução de fins próprios discutidos e definidos coletivamente em um contexto incerto e fragmentário. ${ }^{20}$

Esse contraste entre governo e governança é revelador de uma significativa transformação no quadro político e regulatório atual. Nesse contexto, conforme observa Moreau Defarges, haveria uma espécie de esvaziamento da dimensão política na "era da governança". ${ }^{21}$ Trata-se de

${ }^{17} \mathrm{Cf}$. JESSOP, Bob. The regulation approach, governance and post-Fordism: alternative perspectives on economic and political change? Economy and society, Vol. 24, 3, 1995, p. 317. A respeito, ver: ARNAUD, André-Jean. La gouvernance. Un outil de participation. Paris: Librairie Générale de Droit et de Jurisprudence-Lextenso, 2014, p. 23-24.

${ }^{18}$ Cf. ARNAUD, André-Jean. La gouvernance. Un outil de participation. Paris:

Librairie Générale de Droit et de Jurisprudence-Lextenso, 2014, p. 23-24.

${ }^{19} \mathrm{Cf}$. DELMAS-MARTY, Mireille. Les forces imaginantes du droit. 1, le relatif et l'universel. Paris: Seuil, 2004, p. 267-270; e DELMAS-MARTY, Mireille. Gouvernance et état de droit. In: Séverine Bellina; Hervé Magro; Violaine de Villemeur (Dirs.). La Gouvernance Démocratique: un nouveau paradigme pour le développement? Paris: Karthala, 2008, p. 215-217.

${ }^{20}$ Cf. LE GALÈS, Patrick. Régulation, gouvernance et territoire. In: Jacques Commaille; Bruno Jobert (Dir.). Les métamorphoses de la régulation politique. Paris: Librairie Générale de Droit et de Jurisprudence, 1998, p. 225. A respeito, ver: ARNAUD, AndréJean. La gouvernance. Un outil de participation. Paris: Librairie Générale de Droit et de Jurisprudence-Lextenso, 2014, p. 24.

${ }^{21}$ Cf. MOREAU DEFARGES, Philippe. La gouvernance. $5^{e}$ éd. Paris: Presses Universitaires de France, 2015, p. 27. 
um processo bastante controvertido em meio ao qual se observaria um progressivo deslocamento do poder do plano do governo soberano para o da governança eficaz. ${ }^{22}$ Alain Supiot descreve esse processo em termos de uma progressiva substituição do "governo pelas leis" pela "governança pelos números." Segundo o autor, o "governo pelas leis" referir-se-ia ao reino das regras gerais e abstratas que garantem a identidade, as liberdades e os deveres de cada um. Enquanto tal, ele repousaria sobre a faculdade de julgamento, ou seja, sobre operações de "qualificação jurídica", consistentes em distinguir situações diversas e submetê-las a regras diferentes, e de "interpretação" de textos cujo sentido não pode nunca ser peremptoriamente fixado. Por seu turno, a "governança pelos números" remeteria à autorregulação das sociedades, repousando sobre o cálculo, ou seja, sobre operações de "quantificação" (consistentes em conduzir seres e situações diferentes a um denominador comum) e de "programação de comportamentos" a partir de técnicas de aferição de performances, benchmarking, ranking etc. ${ }^{23}$

Conforme enfatiza Alain Supiot, esse processo de progressiva redução da diversidade dos seres e das coisas a uma quantidade mensurável seria inerente ao projeto de um "mercado total" que, enquanto tal, abarcaria todos os homens e todos os produtos do planeta, mediante a abolição progressiva das fronteiras comerciais de cada país para, a partir daí, ser possível tirar proveito de "vantagens comparativas" ${ }^{24}$ Não cabe analisar aqui o que está implicado nessa tese, especialmente no que concerne ao impacto da expansão da lógica de mercado sobre a justiça social. Para os propósitos deste artigo cumpre apenas notar que a passagem do "governo pelas leis" para a "governança pelos números" também se expressa em uma progressiva substituição da dura lex pela soft law. ${ }^{25}$

${ }^{22}$ Cf. SUPIOT, Alain. Homo juridicus: Essai sur la fonction anthropologique du Droit. Paris: Seuil, 2005, p. 227.

${ }^{23}$ Cf. SUPIOT, Alain. L'Esprit de Philadelphie: la justice sociale face au marché total. Paris: Seuil, 2010, p. 77-78.

${ }^{24}$ Cf. SUPIOT, Alain. L'Esprit de Philadelphie: la justice sociale face au marché total. Paris: Seuil, 2010, p. 78.

${ }^{25}$ Supiot observa que "la dura lex du Droit romain laisse alors place à la douceur de règles conventionnelles (soft law) [...]."SUPIOT, Alain. Homo juridicus: Essai sur la fonction anthropologique du Droit. Paris: Seuil, 2005, p. 271. A respeito, ver também: MOREAU DEFARGES, Philippe. La gouvernance. $5^{e}$ éd. Paris: Presses Universitaires de France, 2015, p. 60-61. 


\section{O FENÔMENO DA GOVERNANÇA ENFOCADO EM SUAS MÚltiPlas ForMAS DE EXPRESSÃo}

Apesar de ostentarem uma miríade de abordagens distintas acerca da governança, as análises sociológicas tendem a enfocá-la, conceitualmente, a partir da ênfase em suas múltiplas formas de expressão. ${ }^{26}$ Conforme

${ }^{26}$ Abordagens concisas, porém bastante elucidativas acerca da governança podem ser encontradas no Dictionnaire de la globalisation, publicado sob a direção de André-Jean Arnaud. Nesse sentido, ver: ARNAUD, André-Jean. Gouvernance (Bonne-). Gouvernance. In: André-Jean Arnaud (Dir.). Dictionnaire de la Globalisation: Droit, Science Politique, Sciences Sociales. Paris: Librairie Générale de Droit et de Jurisprudence, 2010, p. 269-270 ; ARNAUD, André-Jean; SIMOULIN, Vincent. Gouvernance. In: André-Jean Arnaud (Dir.). Dictionnaire de la Globalisation: Droit, Science Politique, Sciences Sociales. Paris: Librairie Générale de Droit et de Jurisprudence, 2010, p. 266-269; DELPLANQUE, Marc. Gouvernance Globale. In: André-Jean Arnaud (Dir.). Dictionnaire de la Globalisation: Droit, Science Politique, Sciences Sociales. Paris: Librairie Générale de Droit et de Jurisprudence, 2010, p. 272275; XUE-BACQUET, Beinan; COLLETS, Gabriel. Gouvernance d'entreprise. In: André-Jean Arnaud (Dir.). Dictionnaire de la Globalisation: Droit, Science Politique, Sciences Sociales. Paris: Librairie Générale de Droit et de Jurisprudence, 2010, p. 270272. No contexto da discussão anglófona ver, por exemplo: HELD, David. Democracy and the Global Order: from the Modern State to Cosmopolitan Governance. Stanford, CA: Stanford University Press, 1995; HELD, David. Reframing Global Governance: Apocalypse Soon or Reform! New Political Economy, Vol. 11, 2, 2006, p. 157-176. Para uma análise relativa à responsabilidade social da empresa e da governança solidária no Brasil, ver: CAPELLER, Wanda. RSE et gouvernances solidaires au Brésil: entre nouvelles formes de socialité et nouveaux espaces publiques. Sociologies Pratiques, Vol 18, 1, 2009, p. 79-90. Para uma definição sintética da governança, ver: DURAN, Patrice. Gouvernance. Politiques et Management Public, Vol. 16, 1, 1998, p. 3-4. Para análises mais extensas, ver: ARNAUD, André-Jean. Critique de la raison juridique 2. Gouvernants sans frontières entre mondialisation et post-mondialisation. Paris: Librairie Générale de Droit et de Jurisprudence, 2003; ARNAUD, André-Jean. Entre modernité et mondialisation : leçons d'histoire de la philosophie du droit et de l'État. 2ª ed. Paris: Librairie Générale de Droit et de Jurisprudence, 2004; ARNAUD, André-Jean. La gouvernance. Un outil de participation. Paris: Librairie Générale de Droit et de Jurisprudence-Lextenso, 2014. No Brasil, ver, por exemplo: LOCHAGIN, Gabriel Loretto. Lições latino-americanas para um mundo em crise: apontamentos para a governança internacional da dívida 
Jacques Chevallier, uma análise adequada da governança, além da problematização da clivagem entre público e privado, implica sua apreensão a partir de seus vários níveis (internacional, regional, nacional e local) de ação coletiva (multi-level Governance). ${ }^{27}$ André-Jean Arnaud, ao sublinhar as várias facetas de expressão do fenômeno da governança, observa, inclusive, o caráter problemático de se utilizar o termo no singular. ${ }^{28}$ Essa preocupação em explicitar a variedade das formas expressivas da governança estrutura o livro intitulado La gouvernance. Un outil de participation, no qual se encontra a abordagem mais sistematizada e ampla do autor sobre esse tema. ${ }^{29}$ Assim, à guisa de ilustração do modo pelo qual o fenômeno da governança, em suas múltiplas formas de expressão, é enfocado pelas abordagens sociológicas que a ele se dirigem, será feita a seguir uma breve reconstrução da análise realizada por André-Jean Arnaud uma vez que ela, a partir de um amplo diálogo com a literatura especializada, consigna um profundo tratamento dessa temática. ${ }^{30}$

pública. In: Ricardo Lagos (Coord.); Mireya Dávila; Fabíola Wüst Zibetti (Orgs.). A América Latina no Mundo: desenvolvimento regional e governança internacional. São Paulo, SP: EDUSP, 2014, p. 225-237; OLIVEIRA, Alessandra Cavalcante de. Aliança do Pacífico: desenvolvimento regional e governança internacional. In: Ricardo Lagos (Coord.); Mireya Dávila; Fabíola Wüst Zibetti (Orgs.). A América Latina no Mundo: desenvolvimento regional e governança internacional. São Paulo, SP: EDUSP, 2014, p. 213-224; PUCCI, Rafael Diniz. Governança ambiental e sistema financeiro internacional: significantes e significados de complexa comunicação na agenda contemporânea. Revista da Faculdade de Direito da USP, Vol. 110, 2015, p. 641-673.

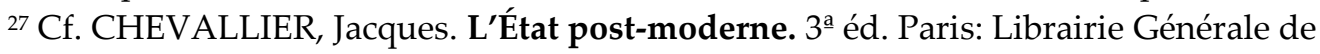
Droit et de Jurisprudence, 2008, p. 240. Conforme ressaltam que Thierry Delpeuch, Laurence Dumoulin e Claire de Galembert, "cette gouvernance multi-niveaux, dont il n'est pas rare qu'elle court-circuite le système de décision intergouvernemental, donne lieu à des 'boucles étranges' dans la chaîne de production des normes". DELPEUCH, Thierry; DUMOULIN, Laurence; GALEMBERT, Claire de. Sociologie du droit et de la justice. Paris: Armand Colin, 2014, p. 167.

${ }^{28} \mathrm{Cf}$. ARNAUD, André-Jean. Critique de la raison juridique 2. Gouvernants sans frontières entre mondialisation et post-mondialisation. Paris: Librairie Générale de Droit et de Jurisprudence, 2003, p. 333.

${ }^{29}$ Cf. ARNAUD, André-Jean. La gouvernance. Un outil de participation. Paris: Librairie Générale de Droit et de Jurisprudence-Lextenso, 2014, p. 215.

30 Para uma análise da governança na obra de André-Jean Arnaud, ver: VILLAS BÔAS FILHO, Orlando. O impacto da governança sobre a regulação jurídica contemporânea: uma abordagem a partir de André-Jean Arnaud. Revista Eletrónica Direito e 


\section{A Governança Empresarial/Corporativa}

André-Jean Arnaud enfoca, preliminarmente, a progressiva expansão e imposição da governança empresarial como modelo de gestão da complexidade. ${ }^{31}$ Assim, sublinhando que a ideia de um novo modelo de gestão empresarial provém do contexto norte-americano, ressalta que, nessa seara, a governança poderia ser entendida, em termos gerais, como a organização e a repartição de poderes entre diferentes instâncias de uma empresa. Como decorrência, ela expressaria um conjunto de procedimentos e de estruturas cuja finalidade seria gerir eficazmente os negócios empresariais de modo a assegurar transparência e equilíbrio de poderes entre administradores, proprietários e seus representantes. ${ }^{32}$ Essa tendência de gestão, que expressaria a superação da tradicional onipotência patronal mediante a introdução massiva de um conjunto de stakeholders, seria passível de implementação a partir da instauração de mecanismos internos e externos de controle. ${ }^{33} \mathrm{~A}$ distinção entre funções de execução e de controle seria determinante à consecução dessa finalidade. Desse modo, para lidar com a complexa dinâmica empresarial, a governança de empresas, nascida da corporate governance, afigura-se como um instrumento de gestão que precisa garantir equilíbrio

Sociedade - REDES, Vol. 4, 1, 2016; e VILLAS BÔAS FILHO, Orlando. As

transformações da regulação jurídica na sociedade contemporânea: a governança como paradigma. Revista Direito GV, Vol. 12, 1, 2016. Resenha de: ARNAUD, André-Jean.

La gouvernance. Un outil de participation. Paris: Librairie Générale de Droit et de Jurisprudence-Lextenso, 2014.

${ }^{31}$ Sobre a governança empresarial, ver: XUE-BACQUET, Beinan; COLLETS, Gabriel. Gouvernance d'entreprise. In: André-Jean Arnaud (Dir.). Dictionnaire de la Globalisation: Droit, Science Politique, Sciences Sociales. Paris: Librairie Générale de Droit et de Jurisprudence, 2010, p. 270-272.

${ }^{32}$ Cf. ARNAUD, André-Jean. La gouvernance. Un outil de participation. Paris: Librairie Générale de Droit et de Jurisprudence-Lextenso, 2014, p. 33. A respeito, ver também: MOREAU DEFARGES, Philippe. La gouvernance. $5^{\mathrm{e}}$ éd. Paris: Presses Universitaires de France, 2015, p. 32-36.

${ }^{33}$ Para uma análise da questão relativa aos shareholders e stakeholders no âmbito da obra de Anthony Giddens, ver: CAPELLER, Wanda. Relire Giddens: Entre sociologie et politique. Paris: Librairie Générale de Droit et de Jurisprudence, 2011, p. 130-133. Para uma análise relativa à responsabilidade social da empresa e da governança solidária no Brasil, ver: CAPELLER, Wanda. RSE et gouvernances solidaires au Brésil: entre nouvelles formes de socialité et nouveaux espaces publiques. Sociologies Pratiques, Vol 18, 1, 2009, p. 79-90. 
de poderes e de direitos, transparência e eficácia. ${ }^{34}$

Portanto, a governança empresarial integrar-se-ia a um conjunto de dispositivos de regulação econômica e financeira com a finalidade de assegurar a boa gestão das empresas em um contexto marcado pela globalização econômica. Tais dispositivos, entretanto, não são necessariamente estabelecidos pela lei. Aliás, aludindo à progressiva inserção da governança empresarial no contexto da globalização, AndréJean Arnaud sublinha sua relação com a soft law (normatividade flexível que expressa o progressivo descentramento da regulação jurídica de sua forma estatal de expressão). ${ }^{35}$ Por esse motivo, Philippe Moreau Defarges associa a governança empresarial às transformações experimentadas pelo capitalismo na contemporaneidade. ${ }^{36}$ É, aliás, nesse contexto que, conforme já ressaltado, Alain Supiot observa que "o governo pelas leis cede espaço à governança pelos números." ${ }^{37}$

\section{A Governança Global}

André-Jean Arnaud ressalta a passagem (não ocasional) da corporate governance para a global governance, salientando a importância das contribuições dos economistas Oliver Williamson, John Williamson e

${ }^{34}$ Cf. ARNAUD, André-Jean. La gouvernance. Un outil de participation. Paris:

Librairie Générale de Droit et de Jurisprudence-Lextenso, 2014, p. 43-45. Para uma abordagem crítica à questão da transparência no âmbito da governança corporativa, ver: XIFRA, Jordi. ¿Qué es transparencia (si existe en relaciones públicas)? In: Luiz Alberto de Farias; Valéria de Siqueira Castro Lopes (Orgs.). Comunicação,

Governança e Organizações. Porto Alegre, RS: ediPUCRS, 2016, p. 19-30.

${ }^{35}$ Cf. ARNAUD, André-Jean. La gouvernance. Un outil de participation. Paris:

Librairie Générale de Droit et de Jurisprudence-Lextenso, 2014, p. 47. Para uma análise da soft law como mecanismo de regulação flexível e de significativa incidência no contexto transnacional, a partir da tradição à qual o autor mais diretamente se insere, ver, por exemplo: CHEVALLIER, Jacques. L'État post-moderne. $3^{\underline{a}}$ éd. Paris: Librairie Générale de Droit et de Jurisprudence, 2008, p. 143-146; DELMAS-MARTY, Mireille.

Le flou du droit: du Code Pénal aux Droits de 1'Homme. Paris: Presses Universitaires de France, 2004, p. 21-25; DELPEUCH, Thierry; DUMOULIN, Laurence; GALEMBERT, Claire de. Sociologie du droit et de la justice. Paris: Armand Colin, 2014, p. 259-261.

${ }^{36}$ Cf. MOREAU DEFARGES, Philippe. La gouvernance. $5^{\mathrm{e}}$ éd. Paris: Presses

Universitaires de France, 2015, p. 35.

${ }^{37}$ Cf. SUPIOT, Alain. L'Esprit de Philadelphie: la justice sociale face au marché total. Paris: Seuil, 2010, p. 77-78. 
Joseph Stiglitz ao desenvolvimento da governança global. Para tanto, destaca que o estabelecimento das principais instituições financeiras internacionais em Washington, quando do término da Segunda Guerra Mundial, teria ocasionado a natural influência do ambiente e da cultura econômica dos EUA na montagem de tais instituições. Como decorrência, a governança global teria sido concebida, em seu conjunto, como a gestão dos negócios mundiais no nível das organizações e das agências internacionais. Nesse sentido, o funcionamento de tais instituições (egressas de Bretton Woods) consistiria essencialmente no enquadramento da atividade soberana dos Estados pelos regimes multilaterais de governança, a partir dos princípios componentes do que se convencionou designar "Consenso de Washington": disciplina fiscal; abertura comercial; estímulo a investimentos estrangeiros; privatização de empresas públicas; desregulação e respeito ao direito de propriedade. ${ }^{38}$

Tais princípios, oficialmente assumidos pelo Banco Mundial e pelo Fundo Monetário Internacional, foram convertidos em imperativos administrativos que deveriam nortear as políticas dos países (especialmente os endividados) em nome do que se convencionou designar de good governance, noção, aliás, que se tornou fundamental no âmbito da governança global, na medida em que assumiu o papel de um paradigma de referência para a avaliação das economias dos países por parte das autoridades financeiras internacionais. A noção de good governance, com sua inequívoca carga prescritiva, encontra, como contraponto, a de poor governance, mobilizada para a avaliação dos Estados em matéria de corrupção e de criminalidade global. ${ }^{39}$ Contudo,

${ }^{38}$ Cf. ARNAUD, André-Jean. La gouvernance. Un outil de participation. Paris:

Librairie Générale de Droit et de Jurisprudence-Lextenso, 2014, p. 61-63. David Held sublinha especialmente a importância da governança para o enfrentamento de problemas e dilemas globais que se impõem na contemporaneidade. Cf. HELD, David. Reframing Global Governance: Apocalypse Soon or Reform! New Political Economy, Vol. 11, 2, 2006, p. 157-176. A respeito, ver também: DELPLANQUE, Marc. Gouvernance Globale. In: André-Jean Arnaud (Dir.). Dictionnaire de la Globalisation: Droit, Science Politique, Sciences Sociales. Paris: Librairie Générale de Droit et de Jurisprudence, 2010, p. 272-275; e MOREAU DEFARGES, Philippe. La gouvernance. $5^{\mathrm{e}}$ éd. Paris: Presses Universitaires de France, 2015, p. 42-49.

${ }^{39}$ Note-se que, como contraponto da noção de good governance, também é utilizada a expressão bad governance. Cf. ARNAUD, André-Jean. La gouvernance. Un outil de participation. Paris: Librairie Générale de Droit et de Jurisprudence-Lextenso, 2014, p. 68-74. A respeito, ver também: MOREAU DEFARGES, Philippe. La gouvernance. $5^{\mathrm{e}}$ éd. Paris: Presses Universitaires de France, 2015, p. 36-42. Para análises críticas à chamada "boa governança", ver, por exemplo: MATTEI, Ugo; NADER, Laura.

2 JOURNAL OF INSTITUTIONAL STUDIES 2 (2016) 
André-Jean Arnaud enfatiza que a governança global não seria apenas um instrumento adstrito ao âmbito financeiro, uma vez que assegurar boas relações no plano internacional permitiria, acima de tudo, garantir a "paz mundial". Assim, nessa perspectiva, a governança global assumiria também a dimensão estratégica de promoção da segurança mundial a partir do impulso à cooperação, ao entendimento e à moderação mútua entre os Estados nacionais, o que, segundo o autor, estaria expresso nos capítulos VI e VII da Carta da ONU, que tratam da resolução pacífica dos conflitos e divergências e das ações relativas às ameaças à paz, ruptura da paz e atos de agressão. ${ }^{40}$ É certo que, seguindo as considerações de Laura Nader e Ugo Mattei, não se pode descartar que essas proclamadas virtudes da governança global podem figurar como sustentação retórica a uma "reabilitação moral do imperialismo". ${ }^{41}$

De todo modo, ao destacar que a governança implica a superação de uma forma de gestão piramidal e autoritária, André-Jean Arnaud sublinha que ela expressaria a substituição progressiva de um sistema top down de tomada de decisão por um sistema bottom up, caracterizado pela ausência de uma produção normativa ordenada e sem atos de governo

Plunder: when the rule of law is illegal. Oxford: Blackwell Publishing, 2008, p. 23/89/143-144; EBERHARD, Christoph. Le droit au miroir des cultures: pour une autre mondialisation. Paris: Librairie Générale de Droit et de Jurisprudence-Lextenso, 2010, p. 191; EBERHARD, Christoph. O Direito no mundo globalizado: em direção à "boa governança" através do diálogo intercultural. Direito, Estado e Sociedade, No. 33, 2008, p. 10.

${ }^{40}$ Cf. ARNAUD, André-Jean. La gouvernance. Un outil de participation. Paris: Librairie Générale de Droit et de Jurisprudence-Lextenso, 2014, p. 74-79. A respeito, ver também: MOREAU DEFARGES, Philippe. La gouvernance. $5^{e}$ éd. Paris: Presses Universitaires de France, 2015, p. 26-27/44.

${ }^{41}$ Corroborando as considerações de Issa Shivji, Laura Nader e Ugo Mattei denunciam essa "reabilitação moral do imperialismo". Segundo Shivji, "the moral rehabilitation of imperialism was first and foremost ideological which in turn was constructed on neoliberal economic precepts - 'free' market, privatisation, liberalisation, etc., the so-called Washington consensus. Human rights, NGOs, good governance, multiparty democracy and rule of law were all rolled together". SHIVJI, Issa. Law's Empire and Empire's Lawlessness: Beyond the Anglo-American Law. Law, Social Justice \& Global Development Journal (LGD), No. 1, 2003, p. 3. Disponível em: $<$ http://elj.warwick.ac.uk/global/03-1/shivji.html>. Acesso em: 28 de janeiro de 2017. Cf. MATTEI, Ugo; NADER, Laura. Plunder: when the rule of law is illegal. Oxford: Blackwell Publishing, 2008, p. 22-23. 
impostos a partir de instâncias centrais e de modo verticalizado. ${ }^{42}$ Estarse-ia, assim, diante de uma passagem da "pirâmide" à "rede", em meio à qual agências multilaterais, ONGs e a sociedade civil se tornam cada vez mais atuantes e decisivas no estabelecimentos de pautas de interesse comum a serem implementadas em nível global, entre as quais, o autor destaca, para fins de sua análise, a questão ecológica. Contudo, a governança global - diferentemente do que ocorre com os governos, cujas decisões se fundam em normas impositivas do direito positivo enfrentaria, no que concerne aos instrumentos de que dispõem os atores que com ela operam, problemas decorrentes do fato de que a regulação produzida pelas organizações internacionais e globais teria apenas um caráter de soft law. ${ }^{43}$ Assim, em diversas hipóteses, os standards e os indicadores que compõem a soft law demandam a intervenção dos Estados para se converterem em normas de direito impositivas. Apesar disso, em diversos domínios - da Organização Mundial do Comércio ao Banco Mundial, passando pelas normas de certificação ISO produzidas pela Organização Internacional de Normalização, pelos indicadores das Agências de Notação Financeira Internacional, tais como Fitch Ratings, Moody's e Standard \& Poors ou pelas normas criadas por entidades como a AFNOR - a intervenção estatal não é indispensável para que tais regulações assumam imposição efetiva. ${ }^{44}$

${ }^{42}$ Cf. ARNAUD, André-Jean. La gouvernance. Un outil de participation. Paris: Librairie Générale de Droit et de Jurisprudence-Lextenso, 2014, p. 80 e 90 . Sobre essa temática, ver também: ARNAUD, André-Jean. Entre modernité et mondialisation : leçons d'histoire de la philosophie du droit et de l'État. $2^{\underline{a}}$ ed. Paris: Librairie Générale de Droit et de Jurisprudence, 2004, p. 142 e ss.; ARNAUD, André-Jean. Critique de la raison juridique 2. Gouvernants sans frontières entre mondialisation et post-mondialisation. Paris: Librairie Générale de Droit et de Jurisprudence, 2003, p. 177 e ss. Essa questão é também muito bem abordada por Jacques Commaille. A respeito, ver: COMMAILLE, Jacques. À quoi nous sert le droit? Paris: Gallimard, 2015, p. 30. No Brasil, ver: FARIA, José Eduardo. O Estado e o Direito depois da Crise. São Paulo, SP: Saraiva, 2011, p. 50-52.

${ }^{43}$ Cf. DELMAS-MARTY, Mireille. Les forces imaginantes du droit. 2, le pluralisme ordonné. Paris: Seuil, 2006, p. 177-178/189-190/266.

${ }^{44}$ Cf. ARNAUD, André-Jean. La gouvernance. Un outil de participation. Paris: Librairie Générale de Droit et de Jurisprudence-Lextenso, 2014, p. 103-109. A respeito, ver também: FARIA, José Eduardo. Sociologia jurídica: direito e conjuntura. $2^{\mathrm{a}}$ ed. São Paulo, SP: Saraiva, 2010, p. 19-20; FARIA, José Eduardo. O Estado e o Direito depois da Crise. São Paulo, SP: Saraiva, 2011, p. 52-56; DELPEUCH, Thierry; DUMOULIN, Laurence; GALEMBERT, Claire de. Sociologie du droit et de la justice. 


\section{A Governança dos Blocos Regionais}

A governança também se faz presente no âmbito dos blocos regionais. É o que André-Jean Arnaud procura explicitar ao aludir à experiência da gouvernance européenne. ${ }^{45}$ Assim, com o intuito de especificar a particularidade da experiência europeia diante da ocorrida nos demais blocos regionais, em que se observa uma articulação de caráter essencialmente econômico e sem pretensão política, André-Jean Arnaud sublinha dois aspectos que, em seu entendimento, seriam decisivos: a) antes de ser o berço do moderno pensamento jurídico e político, a Europa teria sido, ao longo de sua história, uma encruzilhada de diferentes tradições sociais e culturais. Assim, ela teria se construído a partir da assunção desse pluralismo constitutivo de sua história; b) para além de uma simples coalizão econômica, a União Europeia constituiria uma "Federação plurinacional", fundada em um acordo cuja natureza decorreria do compromisso de preservação das identidades culturais e nacionais que lhe são constitutivas, não havendo, assim, um "povo europeu" nem muito menos um governo para geri-lo. ${ }^{46}$ Segundo o autor, em virtude dessas particularidades, a União Europeia não seria passível de ser gerida mediante o processo top down que caracteriza o "governo" na tradição moderna dos regimes de democracia representativa. Imporse-ia a ela, por conseguinte, a governança como instrumento de gestão. ${ }^{47}$

Aludindo ao Livro branco sobre a governança europeia, em que se encontra consignado que a noção de governança designa as regras, os processos e os comportamentos que influenciam o exercício dos poderes no âmbito europeu, André-Jean Arnaud distingue dois aspectos fundamentais relativamente a esse contexto: a) a governança no plano da gestão da União e da participação dos Estados; b) a governança como

Paris: Armand Colin, 2014, p. 261; MOREAU DEFARGES, Philippe. La gouvernance. 5e éd. Paris: Presses Universitaires de France, 2015, p. 65.

${ }^{45}$ Cf. ARNAUD, André-Jean. La gouvernance. Un outil de participation. Paris: Librairie Générale de Droit et de Jurisprudence-Lextenso, 2014, p. 114 e ss.

${ }^{46}$ Cumpre notar que André-Jean Arnaud, quando mobiliza a noção de "Federação plurinacional" (Fédération plurinationale), apoia-se no texto ainda inédito de Hugues Dumont, intitulado "L'Union européenne, une Fédération plurinationale fondée sur un pacte constitutionnel". Cf. ARNAUD, André-Jean. La gouvernance. Un outil de participation. Paris: Librairie Générale de Droit et de Jurisprudence-Lextenso, 2014, p. 115.

${ }^{47}$ Cf. ARNAUD, André-Jean. La gouvernance. Un outil de participation. Paris: Librairie Générale de Droit et de Jurisprudence-Lextenso, 2014, p. 116. 
participação mais efetiva e qualificada dos cidadãos europeus. ${ }^{48}$ Sublinha, entretanto, as diversas dificuldades que expressam as defasagens entre $o$ que se proclama no plano ideal e o que se realiza no plano real. Segundo Arnaud, o cidadão ordinário estaria, por via de regra, distante do funcionamento da governança. Além disso, em sua abordagem, enfocamse as ambivalências (e, portanto, os perigos) das redes de ação pública e a importância atribuída à expertise no contexto da governança europeia. ${ }^{49}$

Ao longo de seu exame acerca da governança no âmbito regional, André-Jean Arnaud descentra-se da União Europeia e, a partir de uma abordagem contrastada, especialmente no que concerne ao déficit de participação dos cidadãos, enfoca a experiência desenvolvida no Mercosul. Considerando, evidentemente, as particularidades desses dois blocos, o autor aponta os paralelos existentes entre eles, especialmente no que tange à pretensão de construção de dois espaços regionais de cooperação transnacional com aspirações análogas de integração econômica e de constituição de um projeto político mais global. A esse respeito, enfatiza que, apesar dos indiscutíveis avanços ocorridos tanto na União Europeia como no Mercosul, ambos os blocos constituiriam, ainda, laboratórios de experimentação para a governança regional. A partir desse contraste, observa que o déficit de participação real dos cidadãos aparece como o principal entrave a um desenvolvimento mais consequente da governança regional, entendida como dinâmica complexa das relações e inter-relações transformadoras que articulam instituições, Estados-membros, sociedade civil, grupos de interesse, lobbies e redes sociais. ${ }^{50}$

${ }^{48}$ Cf. ARNAUD, André-Jean. La gouvernance. Un outil de participation. Paris: Librairie Générale de Droit et de Jurisprudence-Lextenso, 2014, p. 123-130. Acerca da experiência europeia no quadro da governança regional, ver também: DELMASMARTY, Mireille. Les forces imaginantes du droit. 1, le relatif et l'universel. Paris: Seuil, 2004, p. 71-72/80-82.

${ }^{49}$ Cf. ARNAUD, André-Jean. La gouvernance. Un outil de participation. Paris: Librairie Générale de Droit et de Jurisprudence-Lextenso, 2014, p. 145 e ss. Anne Isla também discute a questão da governança no plano da Comunidade Europeia procurando traçar, a partir daí, as relações entre direito e economia. Cf. ISLA, Anne. Pour une économie institutionnelle et organisationnelle du droit: la gouvernance dans l'Union européenne. Droit et Société, Vol. 54, 2, 2003, p. 353-373.

${ }^{50}$ Cf. ARNAUD, André-Jean. La gouvernance. Un outil de participation. Paris: Librairie Générale de Droit et de Jurisprudence-Lextenso, 2014, p. 158-166. A respeito, ver: DELMAS-MARTY, Mireille. Les forces imaginantes du droit. 1, le relatif et l'universel. Paris: Seuil, 2004, p. 81. 


\section{A Governança Nacional}

A governança no plano nacional é a que mais diretamente se atrela a questões culturais. Assim, a partir de um breve contraste entre a experiência político-administrativa norte-americana e a francesa, AndréJean Arnaud ressalta que a representação da governança como uma ameaça à soberania estatal se expressa, sobretudo, em países nos quais se verifica uma visão cultural centralista do Estado moderno. Contudo, procura sublinhar o fato de que o Estado não poderia mais ser visto como a única instância detentora do poder, ${ }^{51}$ de modo que, com a governança, afigurar-se-ia possível gerir as questões públicas para além do direito estatal, o que, em outras palavras, expressaria a progressiva passagem de uma ação política outrora fundada no governo para outra amparada na governança. ${ }^{52}$ Decorreria daí, inclusive, o declínio da concepção top down que atribui apenas aos governantes a criação do "dever-ser". Observarse-ia, assim, a progressiva substituição, no debate jurídico, dos conceitos clássicos de "governo", "lei" e "regulamentação" pelos de "governança", "políticas públicas", "ação direta", "resolução de conflitos" e,

51 É possível afirmar que, sob esse aspecto, a análise de André-Jean Arnaud problematiza concepções como a de Pierre Bourdieu que, inspirado em Weber, define o Estado como instância detentora do monopólio legítimo da violência física e simbólica. Cf. BOURDIEU, Pierre. Esprits d'État [Genèse et structure du champ bureaucratique]. Actes de la Recherche en Sciences Sociales, Vol. 96-97, 1, 1993, p. 4962; e BOURDIEU, Pierre. Sur l'État. Cours au Collège de France 1989-1992. Paris: Seuil, 2012, p. 14/139/199/204/545/587. A respeito, ver: COMMAILLE, Jacques. À quoi nous sert le droit? Paris: Gallimard, 2015, p. 30; CHEVALLIER, Jacques. L'État postmoderne. 3a éd. Paris: Librairie Générale de Droit et de Jurisprudence, 2008, p. 237-242; ROULAND, Norbert. Nos confins do Direito: Antropologia Jurídica da modernidade. Trad. Maria Ermantina de Almeida Prado Galvão. São Paulo, SP: Martins Fontes, 2003, p. 173-174; e SANTOS, Boaventura de Sousa. A crítica da razão indolente: contra o desperdício da experiência. Para um novo senso comum: a ciência, o direito e a política na transição paradigmática, Vol. 1. $4^{\mathrm{a}}$ ed. São Paulo: Cortez, 2002, p. 206 e ss.

${ }^{52}$ A respeito, ver também: ARNAUD, André-Jean. Entre modernité et mondialisation : leçons d'histoire de la philosophie du droit et de l'État. $2^{a}$ ed. Paris: Librairie Générale de Droit et de Jurisprudence, 2004, p. 146 e ss.; CHEVALLIER, Jacques. L'État post-moderne. $3^{\mathrm{a}}$ éd. Paris: Librairie Générale de Droit et de Jurisprudence, 2008, p. 237-238; SUPIOT, Alain. L'Esprit de Philadelphie: la justice sociale face au marché total. Paris: Seuil, 2010, p. 77-78. 
especialmente, "regulação". 53

Feitas essas ponderações, Arnaud ressalta que, no plano nacional, a governança se expressaria, essencialmente, a partir de três maneiras: a) o desenvolvimento de agências reguladoras; b) a ingerência de uma normatividade advinda de standards e indicadores; c) o incremento de formas de intervenção participativa dos cidadãos. ${ }^{54}$ Não há como recuperar aqui a complexidade das considerações por ele realizadas acerca dessas questões, uma vez que isso implicaria uma digressão incompatível com as dimensões comportadas neste artigo. No entanto, cabe notar que, em meio a essa complexa e detalhada análise, Arnaud enfatiza que a ideia de governança implica a redefinição das funções estatais. Para ele, tal como ocorre nos níveis empresarial, global e regional, também no nacional a governança se expressaria (e deveria ser estudada) como uma dinâmica complexa de relações e inter-relações transformadoras que se tecem entre os diversos âmbitos que constituem o Estado nacional. Nesse sentido, sua implementação supõe que se ponha em questão a concepção de Estado legada pela tradição ocidental..$^{55}$

${ }^{53}$ Cf. ARNAUD, André-Jean. La gouvernance. Un outil de participation. Paris: Librairie Générale de Droit et de Jurisprudence-Lextenso, 2014, p. 180. O conceito de regulação é de grande importância para análise de Arnaud que, em seu último livro, a examina especialmente no âmbito da governança exercida no plano nacional. Para uma definição do conceito, ver, por exemplo: ARNAUD, André-Jean. De la régulation par le droit à l'heure de la globalisation. Quelques observations critiques. Droit et Société, v. 35, 1, 1997, p. 11-35; CHEVALLIER, Jacques. La régulation juridique en question. Droit et Société, Vol. 49, 3, 2001, p. 827-846; e CHEVALLIER, Jacques. L'État post-moderne. $3^{\text {a }}$ éd. Paris: Librairie Générale de Droit et de Jurisprudence, 2008, p. 6162.

${ }^{54}$ Cf. ARNAUD, André-Jean. La gouvernance. Un outil de participation. Paris: Librairie Générale de Droit et de Jurisprudence-Lextenso, 2014, p. 181-182. No que concerne à intervenção participativa dos cidadãos, Arnaud destaca a atuação dos movimentos sociais. Para uma excelente análise dessa questão no Brasil, ver:

CAMPILONGO, Celso Fernandes. Interpretação do Direito e Movimentos Sociais: Hermenêutica do Sistema Jurídico e da Sociedade. Rio de Janeiro, RJ: Elsevier, 2012, p. 9 e ss.

${ }^{55}$ Cf. ARNAUD, André-Jean. La gouvernance. Un outil de participation. Paris: Librairie Générale de Droit et de Jurisprudence-Lextenso, 2014, p. 222. 


\section{A Governança Territorial/Local}

Para analisar a governança territorial, André-Jean Arnaud recupera a ideia de governança "subnacional", proposta por James Nathan Rosenau ${ }^{56}$ Nesse sentido, enfatiza, preliminarmente, que a governança territorial, apesar de enfrentar os mesmos desafios que se impõem à transnacional, caracterizar-se-ia por não poder se estender para além da jurisdição dos Estados em que ela se exerce. Após sublinhar a dificuldade de definição do que seja a governança territorial - especialmente com o desaparecimento do que outrora se designava de "ordem territorial" em virtude da explosão das fronteiras locais, da complexidade engendrada pela progressiva desvinculação das políticas territoriais dos limites jurisdicionais e das escalas tradicionais e da multiplicação dos atores em interação -, André-Jean Arnaud, retomando uma definição proposta por ele e Vincent Simoulin, afirma que a expressão recobriria o conjunto de situações de cooperação entre autoridades públicas, atores privados, associações e cidadãos, não ordenados hierarquicamente, envolvidos na construção, na gestão ou na representação dos territórios em que vivem e em relação ao ambiente exterior. ${ }^{57}$ Para ilustrar o modo pelo qual se desenvolve concretamente essa forma de governança, o autor se propõe a enfocar, em primeiro lugar, seus efeitos transformadores na administração pública local e, em segundo lugar, seu impacto na questão do desenvolvimento sustentável. Portanto, a partir de uma detalhada análise dirigida à realidade brasileira, focaliza, em primeiro lugar, a experiência do orçamento participativo de Porto Alegre, discutindo em que medida ela expressaria um modelo de governança local em meio ao qual se esboçaria um sistema de decisão de perfil bottom up em substituição à lógica top down que se manifesta na dinâmica tradicional das decisões governamentais, ${ }^{58} \mathrm{e}$, em segundo lugar, a experiência da governança no que concerne ao desenvolvimento sustentável na floresta

${ }^{56}$ Conforme Arnaud "dès la fin du siècle écoulé, James Nathan Rosenau, en même temps qu'il définissait la gouvernance transnationale - on le précisait en parlant de gouvernance globale -, donnait une définition de la gouvernance 'subnationale'" ARNAUD, André-Jean. La gouvernance. Un outil de participation. Paris: Librairie Générale de Droit et de Jurisprudence-Lextenso, 2014, p. 223.

${ }^{57}$ Cf. ARNAUD, André-Jean. La gouvernance. Un outil de participation. Paris: Librairie Générale de Droit et de Jurisprudence-Lextenso, 2014, p. 224-227.

${ }^{58}$ Cf. ARNAUD, André-Jean. La gouvernance. Un outil de participation. Paris: Librairie Générale de Droit et de Jurisprudence-Lextenso, 2014, p. 231. A respeito, ver também: MOREAU DEFARGES, Philippe. La gouvernance. $5^{\mathrm{e}}$ éd. Paris: Presses Universitaires de France, 2015, p. 37-38.

2 JOURNAL OF INSTITUTIONAL STUDIES 2 (2016) 
amazônica. ${ }^{59}$

Referindo-se às abordagens que, desde há muito tempo, associam democracia local e participação cidadã, André-Jean Arnaud enfatiza que a governança territorial demanda uma reconfiguração dos poderes entre governantes, sociedade civil e mercado, o que engendra o confronto de diversas "racionalidades políticas". A governança territorial suporia a construção e a manutenção permanente de novos quadros institucionais e o manejo de instrumentos complexos, tais como: procedimentos administrativos e jurídicos, finanças públicas etc. Nesse sentido, demandaria o engajamento dos representantes e a participação dos cidadãos e associações civis (daí, aliás, a necessidade de um processo progressivo de empowerment) ${ }^{60}$ Assim, o autor observa que também no plano territorial a governança implica a redefinição das funções públicas tais como elas foram concebidas tanto pela filosofia jurídica como pela política da época moderna (séculos XVII e XVIII), as quais teriam pautado, desde então, toda a conquista da democracia no Ocidente. ${ }^{61}$

\section{GOVERNANÇA E TOMADA DE DECISÃO}

Após analisar essas diversas formas de expressão da governança, André-Jean Arnaud sublinha seu papel como paradigma de auxílio à tomada de decisão, ressaltando que ela constituiria, em primeiro lugar, uma nova maneira de enfocar a administração dos negócios, públicos e privados, que rompe com a tradição top down desenvolvida no bojo do regime da democracia representativa e, em segundo lugar, um instrumento capaz de proporcionar uma gestão de tipo novo ${ }^{62}$, o que remete a um aspecto fundamental da governança: afigurar-se como um

${ }^{59}$ Cf. ARNAUD, André-Jean. La gouvernance. Un outil de participation. Paris: Librairie Générale de Droit et de Jurisprudence-Lextenso, 2014, p. 258-268.

${ }^{60}$ Cf. ARNAUD, André-Jean. La gouvernance. Un outil de participation. Paris: Librairie Générale de Droit et de Jurisprudence-Lextenso, 2014, p. 269.

${ }^{61}$ Cf. ARNAUD, André-Jean. La gouvernance. Un outil de participation. Paris: Librairie Générale de Droit et de Jurisprudence-Lextenso, 2014, p. 271.

${ }^{62}$ Cf. ARNAUD, André-Jean. La gouvernance. Un outil de participation. Paris: Librairie Générale de Droit et de Jurisprudence-Lextenso, 2014, p. 274. Sobre a predileção por uma democracia participativa enquanto modo de governança dos regimes de regulação, ver: DELPEUCH, Thierry; DUMOULIN, Laurence; GALEMBERT, Claire de. Sociologie du droit et de la justice. Paris: Armand Colin, 2014, p. 264. 
instrumento de participação na tomada de decisões complexas (públicas e privadas) e em todos os níveis, do global ao local. ${ }^{63}$ Nesse tocante, Philippe Moreau Defarges, salienta que, no âmbito da governança, as decisões deixam de figurar como propriedade e poder de um indivíduo ou grupo e passam a resultar de uma negociação permanente entre os atores sociais que, concebidos como partícipes de um vasto jogo, articular-se-iam nos mais diversos âmbitos, tais como os anteriormente elencados. ${ }^{64}$

A respeito, André-Jean Arnaud destaca que, ao ensejar uma ampliação do rol de atores sociais na formulação de decisões complexas relativamente a assuntos de interesse comum e na elaboração de normatividade vinculativa, a governança se expressaria como um instrumento de participação democrática. Aliás, nesse particular, cumpre notar que, segundo Pierre Rosanvallon, a experiência democrática atual demanda cada vez mais uma legitimação não restrita à esfera eleitoralrepresentativa. ${ }^{65}$ É por esse motivo que correlaciona diretamente a experiência democrática e a ideia de governança, pois, conforme observa, o desenvolvimento de formas de implicação dos cidadãos nas decisões que lhes concernem representaria um dos traços fundamentais da evolução recente dos regimes democráticos. ${ }^{66}$ Além do mais, conforme

${ }^{63}$ Cf. ARNAUD, André-Jean. La gouvernance. Un outil de participation. Paris: Librairie Générale de Droit et de Jurisprudence-Lextenso, 2014, p. 279/293-294.

${ }^{64}$ Cf. MOREAU DEFARGES, Philippe. La gouvernance. $5^{\mathrm{e}}$ éd. Paris: Presses Universitaires de France, 2015, p. 4-5.

${ }^{65}$ Segundo Rosanvallon, "la vie des démocraties s'élargit donc de plus en plus au-delà de la sphère électorale-représentative. Il y a dorénavant bien d'autres façons, à la concurrentes et complémentaires de la consécration par les urnes, d'être reconnu comme démocratiquement légitime". ROSANVALLON, Pierre. La légitimité démocratique: impartialité, réflexivité, proximité. Paris: Seuil, 2008, p. 19. Vale notar que essa problemática também é enfatizada por André-Jean Arnaud. A respeito, ver: ARNAUD, André-Jean. Critique de la raison juridique 2. Gouvernants sans frontières entre mondialisation et post-mondialisation. Paris: Librairie Générale de Droit et de Jurisprudence, 2003, p. 283 e ss. A respeito, ver: VILLAS BÔAS FILHO, Orlando. Democracia: a polissemia de um conceito político fundamental. Revista da Faculdade de Direito da USP, Vol. 108, 2013, p. 655/689.

${ }^{66} \mathrm{Cf}$. ROSANVALLON, Pierre. La contre-démocratie: la politique à l'âge de la défiance. Paris: Seuil, 2006, p. 302-305. Relacionando diretamente democracia e governança, Rosanvallon ressalta que "une 'conduite démocratique' de leur part se caractérise par le fait que les décisions soient argumentées et rendues publiques, que les responsabilités soient clairement établies, que l'information soit donnée, que 
também o nota Philippe Moreau Defarges, a transparência - que a governança tende a promover - constitui uma das dimensões fundamentais da modernidade democrática. ${ }^{67}$

Contudo, não se pode considerar a governança uma espécie de panaceia no que concerne à participação mais alargada na tomada de decisões. Conforme observa André-Jean Arnaud, tratando-se da governança, é preciso saber dela se servir e querer fazê-lo. Desvios são, evidentemente, possíveis. A eventual organização de lobbies com o intuito de instrumentalização da governança para fins escusos ou distanciados do interesse geral, por exemplo, não pode ser desconsiderada. Torna-se necessária, portanto, uma vigilância permanente para coibir desvios o que, por sua vez, implica a presença das condições indispensáveis à plena implementação da cidadania. ${ }^{68}$

\section{CONCLUSÃO}

Conforme mencionado, diversos autores enfatizam o caráter paradigmático do conceito de governança no contexto atual. Segundo Philippe Moreau Defarges, a governança, desde o início da década de

l'implication des personnes concernées soit assurée. C'est une exigence de

transparence des principes et des procédures, une obligation de rendre des comptes, la capacité des institutions d'être socialement plus appropriables, c'est-à-dire comprises par tous. La démocratie est toujours un mode de décision ou d'élection, mais également un ensemble de conditions d'appropriation de la vie publique qui passe par l'association des personnes à la prise de décision en même temps que par une méthode organisée de discussion permettant la connaissance par chacun des enjeux politiques. L'idée de gouvernance correspond en partie à cela." ROSANVALLON, Pierre.

Légitimité démocratique et gouvernance. In: L'Institute de Recherche et Débat sur la Gouvernance. Chroniques de la gouvernance, 2009-2010. Paris: Éditions Charles Léopold Mayer, 2009, p. 14.

${ }^{67}$ Cf. MOREAU DEFARGES, Philippe. La gouvernance. $5^{e}$ éd. Paris: Presses Universitaires de France, 2015, p. 105. A respeito, ver também: XIFRA, Jordi. ¿Qué es transparencia (si existe en relaciones públicas)? In: Luiz Alberto de Farias; Valéria de Siqueira Castro Lopes (Orgs.). Comunicação, Governança e Organizações. Porto Alegre, RS: ediPUCRS, 2016, p. 19-30; ORTIZ, Laure. Préface. In: André-Jean Arnaud. La gouvernance. Un outil de participation. Paris: Librairie Générale de Droit et de Jurisprudence-Lextenso, 2014, p. VII.

${ }^{68}$ Cf. ARNAUD, André-Jean. La gouvernance. Un outil de participation. Paris: Librairie Générale de Droit et de Jurisprudence-Lextenso, 2014, p. 298-303. 
1990, teria se imposto progressivamente como um conceito fundamental. ${ }^{69} \mathrm{Em}$ sentido semelhante, Mireille Delmas-Marty refere-se à governança como um "lugar-comum do vocabulário político mundial". ${ }^{70}$ Por sua vez, André-Jean Arnaud enfatiza que o conceito de governança poderia - no complexo contexto da regulação jurídica contemporânea - ser reputado paradigmático, especialmente no que tange à tomada de decisões. Assim, aludindo à clássica concepção de paradigma, proposta por Thomas Kuhn na obra A estrutura das revoluções científicas, Arnaud observa que a governança forneceria um quadro de referência capaz de traduzir velhos problemas em novos termos com o intuito de permitir a obtenção de soluções. ${ }^{71}$ A esse respeito, Wanda Capeller e Vincent Simoulin, baseando-se na noção de "programa de pesquisa", proposta por Jean-Michel Berthelot, ressaltam que a governança - na medida em que abrange os mais diversos domínios, tais como o social, o cultural, o econômico e o jurídico - poderia ser considerada uma matriz conceitual para o diálogo transdisciplinar. ${ }^{72}$

Segundo Wanda Capeller e Vincent Simoulin, a noção de "programa de pesquisa", tal como proposta por Berthelot, serviria, sobretudo, para designar abordagens, métodos e modos de análise. Tratar-se-ia de uma noção que se distancia da de paradigma, tal como formulada por Thomas Kuhn, uma vez que insistiria na continuidade, e não na descontinuidade. Assim, nessa perspectiva, a noção de "programa de pesquisa" indicaria, acima de tudo, um lugar de encontro transdisciplinar, em meio ao qual disciplinas autônomas poderiam dialogar a partir de um debate fértil que as articularia de modo a ensejar a criação de instrumentos analíticos novos não vinculados especificamente a nenhuma delas. Aliás, nesse particular, a própria polissemia do conceito o vocacionaria, como bem observado pelos autores, a figurar como matriz capaz de ensejar o diálogo

${ }^{69}$ Cf. MOREAU DEFARGES, Philippe. La gouvernance. 5e éd. Paris: Presses

Universitaires de France, 2015, p. 7.

${ }^{70} \mathrm{Cf}$. DELMAS-MARTY, Mireille. Les forces imaginantes du droit. 1, le relatif et l'universel. Paris: Seuil, 2004, p. 71; e DELMAS-MARTY, Mireille. Gouvernance et état de droit. In: Séverine Bellina; Hervé Magro; Violaine de Villemeur (Dirs.). La Gouvernance Démocratique: un nouveau paradigme pour le développement? Paris: Karthala, 2008, p. 215.

${ }^{71}$ Cf. ARNAUD, André-Jean. La gouvernance. Un outil de participation. Paris: Librairie Générale de Droit et de Jurisprudence-Lextenso, 2014, p. 293.

${ }^{72}$ Cf. CAPELLER, Wanda; SIMOULIN, Vincent. La gouvernance: du programme de recherche à la transdisciplinarité (Présentation). Droit et Société, v. 54, 2, 2003, p. 301302.

2 JOURNAL OF INSTITUTIONAL STUDIES 2 (2016) 
transdisciplinar. ${ }^{73}$

Entretanto, cumpre notar que diversos autores imputam vagueza e imprecisão ao conceito de governança. Catherine Baron, por exemplo, ao examinar o caráter polissêmico do conceito de governança, ressalta, entre outras coisas, que ele expressaria uma forma de apreensão das novas práticas e representações suscitadas pela globalização. ${ }^{74}$ Analogamente, Étienne Le Roy também sublinha o caráter polissêmico da governança afirmando tratar-se de uma espécie de "mot-valise" ou de "mot girouette". ${ }^{75}$ Assim, seria possível sustentar que o termo "governança" apresentaria os atributos das "palavras plásticas" (Plastikwörter), no sentido em que Uwe Pörksen as define. Seria possível também enxergar nele um tipo de "mot en caoutchouc", tal como Auguste Blanqui se referia a termos sem acepção precisa. ${ }^{76}$ Contudo, como observam Wanda Capeller e Vincent Simoulin, o caráter polissêmico do conceito de governança não constituiria propriamente uma mácula capaz de comprometê-lo. Conforme bem o notam, seria justamente essa polissemia que o permitiria figurar como matriz conceitual para o diálogo transdisciplinar. Assim, dado o enraizamento do conceito em diversos domínios de análise, não seria possível defini-lo peremptoriamente. ${ }^{77}$ Aliás, no que concerne a esse aspecto, cumpre lembrar que, segundo Reinhart Koselleck, a polissemia é inerente aos conceitos, afinal, como já afirmara Nietzsche, só é definível aquilo que não tem história, e esse não

${ }^{73}$ Cf. CAPELLER, Wanda; SIMOULIN, Vincent. La gouvernance: du programme de recherche à la transdisciplinarité (Présentation). Droit et Société, v. 54, 2, 2003, p. 302. ${ }^{74}$ Cf. BARON, Catherine. La gouvernance: débats autour d'un concept polysémique. Droit et Société, Vol. 54, 2, 2003, p. 329-349.

${ }^{75}$ Cf. LE ROY, Étienne. Gouverner la néo-modernité africaine? In: Chistoph Eberhard (Dir.). Le Courage des Alternatives (Cahiers d'Anthropologie du Droit, Hors Série). Paris: Karthala, 2012, p. 186.

${ }^{76}$ Acerca do caráter "plástico" do conceito de governança, ver: VILLAS BÔAS FILHO, Orlando. O impacto da governança sobre a regulação jurídica contemporânea: uma abordagem a partir de André-Jean Arnaud. REDES - Revista Eletrônica Direito e Sociedade, Vol. 4, 1, 2016. Laura Nader e Ugo Mattei aludem à noção de Plastikwörter de Uwe Pörksen ao analisarem a fluidez do conceito de Rule of Law. A respeito, ver: MATTEI, Ugo; NADER, Laura. Plunder: when the rule of law is illegal. Oxford: Blackwell Publishing, 2008, p. 10/217. A expressão "mot en caoutchouc", utilizada por Auguste Blanqui, é recuperada por Kristin Ross em sua análise acerca da democracia. Cf. ROSS, Kristin. Démocratie à vendre. In: Giorgio Agamben et al. (Dir.). Démocratie dans quel état? Paris: La Fabrique ed., 2009, p. 101-121.

77 Cf. CAPELLER, Wanda; SIMOULIN, Vincent. La gouvernance: du programme de recherche à la transdisciplinarité (Présentation). Droit et Société, v. 54, 2, 2003, p. 302.

2 JOURNAL OF INSTITUTIONAL STUDIES 2 (2016) 
é o caso da governança. ${ }^{78}$

\title{
VI. REFERÊNCIAS
}

\author{
ARNAUD, André-Jean. Critique de la raison juridique 1. Où va la \\ sociologie du droit? Paris: Librairie Générale de Droit et de \\ Jurisprudence, 1981.
}

. Critique de la raison juridique 2. Gouvernants sans frontières entre mondialisation et post-mondialisation. Paris: Librairie Générale de Droit et de Jurisprudence, 2003.

. De la régulation par le droit à l'heure de la globalisation. Quelques observations critiques. Droit et Société, v. 35, 1, 1997.

${ }^{78}$ Cf. KOSELLECK, Reinhart. Vergangene Zukunft: Zur Semantik geschichtlicher Zeiten. Frankfurt am Main: Suhrkamp, 1989, p. 120. [trad. port. Futuro Passado: Contribuição à Semântica dos Tempos Históricos. Trad. Wilma Patrícia Maas e Carlos Almeida Pereira. Rio de Janeiro, RJ: Contraponto: Editora PUC-Rio, 2006, p. 109]; e KOSELLECK, Reinhart. Uma História dos Conceitos: Problemas Teóricos e Práticos. Revista Estudos Históricos, Vol. 5, 10, 1992, p. 134. Para uma utilização da Begriffsgeschichte de Koselleck no âmbito jurídico, ver, por exemplo: VILLAS BÔAS FILHO, Orlando. A historicidade da dogmática jurídica: uma abordagem a partir da Begriffsgeschichte de Reinhart Koselleck. In: José Rodrigo Rodriguez; Carlos Eduardo Batalha da Silva e Costa; Samuel Rodriguez Barbosa (Orgs.). Nas fronteiras do formalismo: a função da dogmática jurídica hoje. São Paulo, SP: Saraiva, 2010; VILLAS BÔAS FILHO, Orlando. Direito e liberdade: algumas considerações acerca de uma abordagem atenta à historicidade dos conceitos. In: Eduardo Carlos Bianca Bittar; João Maurício Adeodato (Orgs.). Filosofia e teoria geral do direito: homenagem a Tercio Sampaio Ferraz Junior. São Paulo, SP: Quartier Latin, 2011; e VILLAS BÔAS FILHO, Orlando. Democracia: a polissemia de um conceito político fundamental. Revista da Faculdade de Direito da USP, Vol. 108, 2013. 
. Entre modernité et mondialisation : leçons d'histoire de la philosophie du droit et de $1^{\prime}$ État. $2^{a}$ ed. Paris: Librairie Générale de Droit et de Jurisprudence, 2004.

. Gouvernance (Bonne-). Gouvernance. In: André-Jean Arnaud (Dir.). Dictionnaire de la Globalisation: Droit, Science Politique, Sciences Sociales. Paris: Librairie Générale de Droit et de Jurisprudence, 2010.

. La gouvernance. Un outil de participation. Paris: Librairie Générale de Droit et de Jurisprudence-Lextenso, 2014.

ARNAUD, André-Jean; COTTERRELL, Roger. Comment penser le multiculturalisme en droit? L'Observateur des Nations Unies: revue de 1'Association Française pour les Nations Unies , Vol. 23, 2, 2007.

ARNAUD, André-Jean; SIMOULIN, Vincent. Gouvernance. In: AndréJean Arnaud (Dir.). Dictionnaire de la Globalisation: Droit, Science Politique, Sciences Sociales. Paris: Librairie Générale de Droit et de Jurisprudence, 2010.

BARON, Catherine. La gouvernance: débats autour d'un concept polysémique. Droit et Société, Vol. 54, 2, 2003.

BOURDIEU, Pierre. Esprits d'État [Genèse et structure du champ bureaucratique]. Actes de la Recherche en Sciences Sociales, Vol. 96-97, 1, 1993.

. Sur l'État. Cours au Collège de France 1989-1992. Paris: Seuil, 2012.

CAMPILONGO, Celso Fernandes. Interpretação do Direito e Movimentos Sociais: Hermenêutica do Sistema Jurídico e da Sociedade. Rio de Janeiro, RJ: Elsevier, 2012. 
CAPELLER, Wanda. Relire Giddens: Entre sociologie et politique. Paris: Librairie Générale de Droit et de Jurisprudence, 2011.

. RSE et gouvernances solidaires au Brésil: entre nouvelles formes de socialité et nouveaux espaces publiques. Sociologies Pratiques, Vol 18, 1, 2009.

CAPELLER, Wanda; SIMOULIN, Vincent. La gouvernance: du programme de recherche à la transdisciplinarité (Présentation). Droit et Société, v. 54, 2, 2003.

CHEVALLIER, Jacques. La régulation juridique en question. Droit et Société, Vol. 49, 3, 2001.

. L'État. 2ª ed. Paris: Dalloz, 2011.

. L'État post-moderne. $3^{a}$ éd. Paris: Librairie Générale de Droit et de Jurisprudence, 2008.

COMMAILLE, Jacques. À quoi nous sert le droit? Paris: Gallimard, 2015.

DELMAS-MARTY, Mireille. Gouvernance et état de droit. In: Séverine Bellina; Hervé Magro; Violaine de Villemeur (Dirs.). La Gouvernance Démocratique: un nouveau paradigme pour le développement? Paris: Karthala, 2008.

. Le flou du droit: du Code Pénal aux Droits de l'Homme. Paris: Presses Universitaires de France, 2004.

. Les forces imaginantes du droit. 1, le relatif et l'universel. Paris: Seuil, 2004. 
Les forces imaginantes du droit. 2, le pluralisme ordonné.

Paris: Seuil, 2006.

DELPEUCH, Thierry; DUMOULIN, Laurence; GALEMBERT, Claire de. Sociologie du droit et de la justice. Paris: Armand Colin, 2014.

DELPLANQUE, Marc. Gouvernance Globale. In: André-Jean Arnaud (Dir.). Dictionnaire de la Globalisation: Droit, Science Politique, Sciences Sociales. Paris: Librairie Générale de Droit et de Jurisprudence, 2010.

DUPUY, Claude; LEROUX, Isabelle; WALLET, Frédéric. Conflits, négociation et gouvernance territoriale. Droit et Société, Vol. 54, 2, 2003.

DURAN, Patrice. Gouvernance. Politiques et Management Public, Vol. 16, 1, 1998.

EBERHARD, Christoph. Le droit au miroir des cultures: pour une autre mondialisation. Paris: Librairie Générale de Droit et de JurisprudenceLextenso, 2010.

. O Direito no mundo globalizado: em direção à "boa governança" através do diálogo intercultural. Direito, Estado e Sociedade, No. 33, 2008.

. Vers une gouvernance responsable? Le juriste face aux alternatives émergentes. In: Chistoph Eberhard (Dir.). Le Courage des Alternatives (Cahiers d'Anthropologie du Droit, Hors Série). Paris: Karthala, 2012.

FARIA, José Eduardo. O Estado e o Direito depois da Crise. São Paulo, SP: Saraiva, 2011. 
. Sociologia jurídica: direito e conjuntura. $2^{\underline{a}}$ ed. São Paulo, SP: Saraiva, 2010.

FONSECA, Márcio Alves da. Michel Foucault e o Direito. $2^{2}$ ed. São Paulo, SP: Saraiva, 2012.

FONSECA, Márcio Alves da; GONÇALVES, Guilherme Leite;

CANAPARO, Claudio. Governabilité. In: André-Jean Arnaud (Dir.). Dictionnaire de la Globalisation: Droit, Science Politique, Sciences Sociales. Paris: Librairie Générale de Droit et de Jurisprudence, 2010.

FOUCAULT, Michel. A governamentalidade. In: Michael Foucault. Microfísica do poder. 11ª ed. Rio de Janeiro, RJ: Graal, 1993.

GROS, Frédéric. Michel Foucault. $4^{\mathrm{a}}$ ed. Paris: Presses Universitaires de France, 2010.

HARDT, Michael; NEGRI, Antonio. Empire. Cambridge, MA: Harvard University Press, 2000.

HELD, David. Democracy and the Global Order: from the Modern State to Cosmopolitan Governance. Stanford, CA: Stanford University Press, 1995. . Reframing Global Governance: Apocalypse Soon or Reform! New Political Economy, Vol. 11, 2, 2006.

ISLA, Anne. Pour une économie institutionnelle et organisationnelle du droit: la gouvernance dans l'Union européenne. Droit et Société, Vol. 54, 2, 2003.

JESSOP, Bob. The regulation approach, governance and post-Fordism: alternative perspectives on economic and political change? Economy and society, Vol. 24, 3, 1995. 
KOSELLECK, Reinhart. Uma História dos Conceitos: Problemas Teóricos e Práticos. Revista Estudos Históricos, Vol. 5, 10, 1992.

. Vergangene Zukunft: Zur Semantik geschichtlicher Zeiten. Frankfurt am Main: Suhrkamp, 1989. [trad. port. Futuro Passado: Contribuição à Semântica dos Tempos Históricos. Trad. Wilma Patrícia Maas e Carlos Almeida Pereira. Rio de Janeiro, RJ: Contraponto: Editora PUC-Rio, 2006].

LE GALÈS, Patrick. Régulation, gouvernance et territoire. In: Jacques Commaille; Bruno Jobert (Dir.). Les métamorphoses de la régulation politique. Paris: Librairie Générale de Droit et de Jurisprudence, 1998.

LE ROY, Étienne. Le jeu des lois: une anthropologie "dynamique" du Droit: avec des consignes et des conseils au "jeune joueur juriste". Paris: Librairie Générale de Droit et de Jurisprudence, 1999.

. Gouverner la néo-modernité africaine? In: Chistoph Eberhard (Dir.). Le Courage des Alternatives (Cahiers d'Anthropologie du Droit, Hors Série). Paris: Karthala, 2012.

LOCHAGIN, Gabriel Loretto. Lições latino-americanas para um mundo em crise: apontamentos para a governança internacional da dívida pública. In: Ricardo Lagos (Coord.); Mireya Dávila; Fabíola Wüst Zibetti (Orgs.). A América Latina no Mundo: desenvolvimento regional e governança internacional. São Paulo, SP: EDUSP, 2014.

MATTEI, Ugo; NADER, Laura. Plunder: when the rule of law is illegal. Oxford: Blackwell Publishing, 2008.

MOREAU DEFARGES, Philippe. La gouvernance. $5^{e}$ éd. Paris: Presses Universitaires de France, 2015. 
OLIVEIRA, Alessandra Cavalcante de. Aliança do Pacífico:

desenvolvimento regional e governança internacional. In: Ricardo Lagos (Coord.); Mireya Dávila; Fabíola Wüst Zibetti (Orgs.). A América Latina no Mundo: desenvolvimento regional e governança internacional. São Paulo, SP: EDUSP, 2014.

ORTIZ, Laure. Préface. In: André-Jean Arnaud. La gouvernance. Un outil de participation. Paris: Librairie Générale de Droit et de Jurisprudence-Lextenso, 2014.

PUCCI, Rafael Diniz. Governança ambiental e sistema financeiro internacional: significantes e significados de complexa comunicação na agenda contemporânea. Revista da Faculdade de Direito da USP, Vol. 110, 2015.

ROSANVALLON, Pierre. La contre-démocratie: la politique à l'âge de la défiance. Paris: Seuil, 2006.

La légitimité démocratique: impartialité, réflexivité, proximité. Paris: Seuil, 2008.

. Légitimité démocratique et gouvernance. In: L'Institute de Recherche et Débat sur la Gouvernance. Chroniques de la gouvernance, 2009-2010. Paris: Éditions Charles Léopold Mayer, 2009.

ROSENAU, James. Governança, Ordem e Transformação na Política Mundial. In: James Rosenau; Ernst-Otto Czempiel (Orgs.). Governança sem Governo: ordem e transformação na política mundial. Trad. Sérgio Bath. Brasília, DF: Editora UnB/Imprensa Oficial do Estado, 2000.

ROSS, Kristin. Démocratie à vendre. In: Giorgio Agamben et al. (Dir.). Démocratie dans quel état? Paris: La Fabrique ed., 2009. 
ROULAND, Norbert. Nos confins do Direito: Antropologia Jurídica da modernidade. Trad. Maria Ermantina de Almeida Prado Galvão. São Paulo, SP: Martins Fontes, 2003.

SANTOS, Boaventura de Sousa. A crítica da razão indolente: contra o desperdício da experiência. Para um novo senso comum: a ciência, o direito e a política na transição paradigmática, Vol. 1. $4^{a}$ ed. São Paulo: Cortez, 2002.

SHIVJI, Issa. Law's Empire and Empire's Lawlessness: Beyond the Anglo-American Law. Law, Social Justice \& Global Development Journal (LGD), No. 1, 2003. Disponível em:

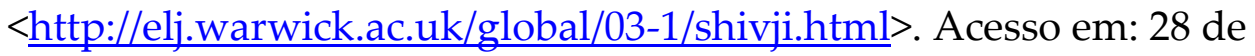
janeiro de 2017.

SIMOULIN, Vincent. La gouvernance et l'action publique: le succès d'une forme simmélienne. Droit et Société, Vol. 54, 2, 2003.

SUPIOT, Alain. Homo juridicus: Essai sur la fonction anthropologique du Droit. Paris: Seuil, 2005.

. L'Esprit de Philadelphie: la justice sociale face au marché total. Paris: Seuil, 2010.

VILLAS BÔAS FILHO, Orlando. A historicidade da dogmática jurídica: uma abordagem a partir da Begriffsgeschichte de Reinhart Koselleck. In: José Rodrigo Rodriguez; Carlos Eduardo Batalha da Silva e Costa; Samuel Rodriguez Barbosa (Orgs.). Nas fronteiras do formalismo: a função da dogmática jurídica hoje. São Paulo, SP: Saraiva, 2010.

- As transformações da regulação jurídica na sociedade contemporânea: a governança como paradigma. Revista Direito GV, Vol. 12, 1, 2016. Resenha de: ARNAUD, André-Jean. La gouvernance. 
Un outil de participation. Paris: Librairie Générale de Droit et de Jurisprudence-Lextenso, 2014.

. Democracia: a polissemia de um conceito político fundamental. Revista da Faculdade de Direito da USP, Vol. 108, 2013.

. Direito e liberdade: algumas considerações acerca de uma abordagem atenta à historicidade dos conceitos. In: João Maurício Adeodato; Eduardo Carlos Bianca Bittar (Orgs.). Filosofia e teoria geral do direito: homenagem a Tercio Sampaio Ferraz Junior. São Paulo, SP: Quartier Latin, 2011.

. O impacto da governança sobre a regulação jurídica contemporânea: uma abordagem a partir de André-Jean Arnaud. Revista Eletrónica Direito e Sociedade - REDES, Vol. 4, 1, 2016.

XIFRA, Jordi. ¿Qué es transparencia (si existe en relaciones públicas)? In: Luiz Alberto de Farias; Valéria de Siqueira Castro Lopes (Orgs.). Comunicação, Governança e Organizações. Porto Alegre, RS: ediPUCRS, 2016.

XUE-BACQUET, Beinan; COLLETS, Gabriel. Gouvernance d'entreprise. In: André-Jean Arnaud (Dir.). Dictionnaire de la Globalisation: Droit, Science Politique, Sciences Sociales. Paris: Librairie Générale de Droit et de Jurisprudence, 2010.

A Governança em suas Múltiplas Formas de Expressão: o delineamento conceitual de um fenômeno complexo Governance in its Multiple Ways of Expression: the conceptual design of a complex phenomenon

Submetido em: 2016-11-13

Aceito em: 2017-01-30 